\title{
Исследование конкурентной сорбции вируса гриппа и бактерий на полимерные материалы
}

\author{
Иванова В.Т. ${ }^{1}$, Морозова Е.О. ${ }^{1}$, Николаева Т.Н. ${ }^{1}$, Бурцева Е.И. ${ }^{1}$, \\ Сапурина И.Ю. ${ }^{2}$, Пронин А.В. ${ }^{1}$ \\ ${ }^{I}$ ФГБУ «Национальный исследовательский центр эпидемиологии и микробиологии имени почетного \\ академика Н. Ф. Гамалеи» Минздрава России, Москва \\ ${ }^{2}$ Институт высокомолекулярных соединений РАН, Санкт-Петербург.
}

Поступила в редакцию 6.03.2018 г.

DOI: https://doi.org/10.17308/sorpchrom.2018.18/507

Проведена последовательная сорбция вируса В/Москва/04/2017 и бактерий, Staphylococcus aureus, Shigella flexneri 2а, на электропроводящие полимеры - полипиррол (РРу) и полианилин (PANI), а также их композиты с наночастицами серебра (PРy-Ag). Показано, что сорбционная активность полимеров, содержащих предварительно сорбированный вирус, в отношении бактерий снижается в следующей последовательности: PANI > PPy-Ag >PANI-Ag > PPy (для Shigella flexneri 2a) и PANI > PANI-Ag> PPy-Ag > PPy (для Staphylococcus aureus). Высокие сорбционные характеристики позволяют использовать данные материалы в качестве фильтров двойного назначения - антивирусных и антибактериальных.

Ключевые слова: вирусы гриппа В, бактерии, адсорбция, полипиррол, полианилин

\section{Investigation of competitive sorption of influenza virus and bacteria on polymeric materials}

\author{
Ivanova V. T. ${ }^{1}$, Morozova E.O. ${ }^{1}$, Nikolaeva T. N. ${ }^{1}$, Burtseva E.I. ${ }^{1}$, \\ Sapurina I.Yu. ${ }^{2}$, Pronin A.V. ${ }^{1}$ \\ ${ }^{1}$ Federal State Budgetary Institution «National Research Center for Epidemiology \& Microbiology named \\ after the honorary academician N.F. Gamaleya» of the Ministry of Health of Russian Federation («N.F. Ga- \\ maleya NRCEM»), Moscow \\ ${ }^{2}$ Institute of Macromolecular Compounds, Russian Academy of Sciences, Saint-Petersburg, Russia.
}

The purpose of this work was to establish the possibility of using electrically conductive polymers to remove different types of micropathogens that are simultaneously present in aqueous media

As sorbents for micropathogens, polypyrrole (PPy) and polyaniline (PANI) composites without and containing silver ions, differing in shape, chemical structure and properties were used. It was sorbed : the virus - influenza $\mathrm{B}$, line $\mathrm{B} / \mathrm{Victoria} / 2 / 87$, similar to the epidemic strains that circulated during the period 2016-2017 in Russia and the world and representatives of bacteria Gram (+)) bacteria - Staphylococcus aureus and Gram-negative (Gram (-)) bacteria: Shigella flexneri 2a. Shigella flexneri 2a. Staphylococcus aureus are conditionally pathogenic microorganisms that are present as in healthy people, as in the many people for several months, and also cause numerous life-threatening zooanthroponotic infections. Shigella flexneri $2 \mathrm{a}$ is the causative agent of an acute intestinal infection, characterized by the development of secondary immunodeficiencies, protracted and chronic forms of infectious diseases, and has a predominantly waterway pathway. Biological models had the differed morphology and structure of proteins.

The experiment was conducted in several stages. At the first stage, sorption of individual micro pathogens was carried out for all types of polymer sorbents: the influenza virus and each type of bacteria. To do 
this, the micropathogen was contacted with the sorbent in the aqueous phase, precipitation was performed with low-speed centrifugation of the complex formed, the activity of the virus in the supernatant and in the complex was analyzed.

To determine the intensity of sorption in solution, a comparison the number of pathogen was made before and after sorption (in the case of influenza viruses of hemagglutinating titers) and (in the case of bacteria) the number of viable bacteria after compared with the control of the corresponding dilutions after seeding of the test samples with $2 \%$ nutrient agar.

In the main experiment, samples containing virus + sorbent complexes were placed in an aqueous solution into which one type of bacteria was added. After contact and centrifugation the efficiency of bacterial sorption for each species was evaluated both in the number of viable bacteria in the supernatant and as in the virus + sorbent + bacteria complex, When comparing the adsorption properties of polymers with the sorbet virus, it was shown that the greatest bacteria sorption activity is decreased in the following sequence of PANI $>$ PPy-Ag $>$ PANI-Ag $>$ PPy sorbents for the bacteria Shigella flexneri $2 \mathrm{a}$ and PANI $>$ PANI-Ag $>$ PPy$\mathrm{Ag}>\mathrm{PPy}$ for bacteria Staphylococcus aureus. High sorption characteristics allow using these materials for two aims - anti viral and anti bacterial filters simultaneously .

Keywords: influenza B viruses, bacteria, adsorption, polypyrrole, polyaniline.

\section{Введение}

Несмотря на принимаемые меры по очистке водопроводной воды, во всем мире чрезвычайно велико распространение через воду инфекционных заболеваний вирусной и бактериальной этиологии. По данным ВОЗ 80\% всех инфекционных болезней в мире связано с низким качеством питьевой воды и неисполнением санитарно-гигиенических норм водоснабжения. Таким образом, остро стоит вопрос поиска недорогих и эффективных сорбентов, обеспечивающих удаление из водной среды широкого спектра патогенов.

Одними из перспективных современных материалов для создания фильтров могут являться электропроводящие полимеры и их композиты. Ранее было показано эффективное удаление из водных сред с помощью полимерных материалов на основе электропроводящих полимеров PРy и PANI как оболочечных вирусов гриппа $\mathrm{A}(\mathrm{H} 1 \mathrm{~N} 1, \mathrm{H} 3 \mathrm{~N} 2 \mathrm{H} 5 \mathrm{~N} 1)$ и B, так и безоболочечных полиовирусов, а также некоторых бактерий [1-5]. Установлено, что мембраны на основе РРу позволяют удалять из водных растворов ряд вирусов животных, включающих полиовирусы, коксаки, эхо, и другие энтеровирусы, рео, рота, гепатит А [6]. Таким образом, электропроводящие полимеры активно связывают патогены из растворов, образуя комплексы. В то же время, электропроводящие полимеры отвечают всем требованиям, предъявляемым к сорбентам: это пористые гидрофильные структуры, хорошо смачиваемые водными средами, но не растворяющиеся в них. Полимеры не токсичны, используются для медицинских целей и, в настоящее время, активно тестируются в качестве сорбентов для очистки воды от солей тяжелых металлов, лекарственных препаратов и красителей $[7,8,9]$. Себестоимость полимеров невысока, поэтому в перспективе они могут стать универсальными сорбентами глубокой очистки воды.

В настоящее время взаимодействие электропроводящих полимеров с патогенами еще недостаточно исследовано и некоторые данные противоречивы. Так установлено, что PРу и PANI по-разному взаимодействуют с клеточными структурами. При исследовании экспрессии генов цитокинов в клетках, в зависимости от структуры цитокина и типа полимера, введенного в клетки Girardi heart, Chang Conjunctiva, Chang Liver, наблюдалась как активация, так и угнетение транскрипции интерферонов [3]. Не изучено пока и перекрестное взаимодействие полимеров с различными типами патогенов, т.е. сорбция на одном полимерном образце представителей бактерий и вирусов. Такое исследование позволило бы ответить на вопрос о возможной конкуренции микробов за места связывания на сорбенте. 
Целью данной работы было установление возможности использования электропроводящих полимеров для удаления разных видов патогенов, одновременно присутствующих в водных средах.

\section{Эксперимент}

Вирус гриппа: B/Москва/04/2017, линии В/Виктория/2/87, подобен эпидемическим штаммам, которые циркулировали в период 2016-2017 гг. в России и мире [10]. Вирус получен из коллекции вирусов гриппа Центра экологии и эпидемиологии гриппа лаборатории гриппа ФГБУ «НИЦЭМ им Н.Ф. Гамалеи» Минздрава России. Вирус культивировали в аллантоисной жидкости куриных эмбрионов, затем ресуспендировали и исследовали в физиологическом растворе. Эффективность сорбции вирусов устанавливали по изменению количества вирусов в физиологическом растворе (200 мкл) до и после контакта вируса с сорбентом (навеска сорбента 4 мг). Изменение содержания вируса гриппа в растворе ( $\mathrm{v}=200$ мкл) до и после контакта с сорбентом определяли по величине гемагглютинирующего (ГА) титра в реакции гемагглютинации, проводимой по общепринятой методике, рекомендованной ВО3, с использованием $0.75 \%$ взвеси эритроцитов $0(\mathrm{I})$ группы крови человека.

Бактерии: Грам(+)) бактерии - Staphylococcus aureus и Грамотрицательные (Грам(-)) бактерии: Shigella flexneri 2a предоставлены из коллекции микроорганизмов лаборатории естественного иммунитета ФГБУ «НИЦЭМ им. Н.Ф. Гамалеи» Минздрава России. Для оценки эффективности сорбции бактерий на выбранные сорбенты использовали метод количественного определения жизнеспособных бактерий на питательной среде (2\% питательный агар - Nutrient agar, Himedia). Взвеси бактерий в концентрации $2 \times 10^{5}$ КОЕ/мл после разведения стерильным физиологическим раствором в количестве 200 мкл для каждого разведения инокулировали с образцами сорбентов. После соответствующей процедуры контакта с сорбентами (в зависимости от цели эксперимента использовали или чистые сорбенты, или комплексы сорбентов с вирусами гриппа) и центрифугирования надосадки и осадки исследованных образцов (100 мкл) высевали на 2\%-питательный агар, а затем инкубировали 24 часа при $\mathrm{T}=37^{\circ} \mathrm{C}$. Далее проводили учет количества жизнеспособных бактерий по сравнению с контролем соответствующих разведений. Начальная концентрация бактерий составляла $2 \times 10^{5} \mathrm{KOE} / \mathrm{cm}^{3}$.

Электропроводящие полимеры и их композиты с Ag: Полипиррол (РРу) получен одностадийным методом окислительной полимеризации пиррола под действием хлорного железа в водном растворе. После высаживания на фильтр полимер промыт водой и высушен до постоянного веса при комнатной температуре. Образец состоял из однотипных сферических частиц РРу диаметром 100 нм (рис.1б). Полипиррол, содержащий 10-15\% веса серебра (РPy-Ag), получен путем высаживания наночастиц серебра на полимерную матрицу из водного раствора соли $\mathrm{AgNO}_{3}$ [11].

Полианилин (PANI) получен методом окислительной полимеризации анилина под действием персульфата аммония в кислой водной среде при комнатной температуре $[1,12]$. Он представлял собой черный порошкообразный осадок, который выделен фильтрованием с количественным выходом, близким к $100 \%$. Полимер отмыт от побочных продуктов разложения окислителя раствором соляной кислоты, затем высушен на воздухе до постоянного веса. PANI-Ag, содержащий сферические частицы серебра диаметром 20-60 нм в количестве 10-15 \% веса, получен при обработке РАNI раствором азотнокислого серебра [13]. На рис.1 представлена химическая формула и изображение полимеров, полученное методом электронной сканирующей мик- 
роскопии. рис.1 показывает, что сорбенты на основе электропроводящих полимеров отличались химической структурой и составом.
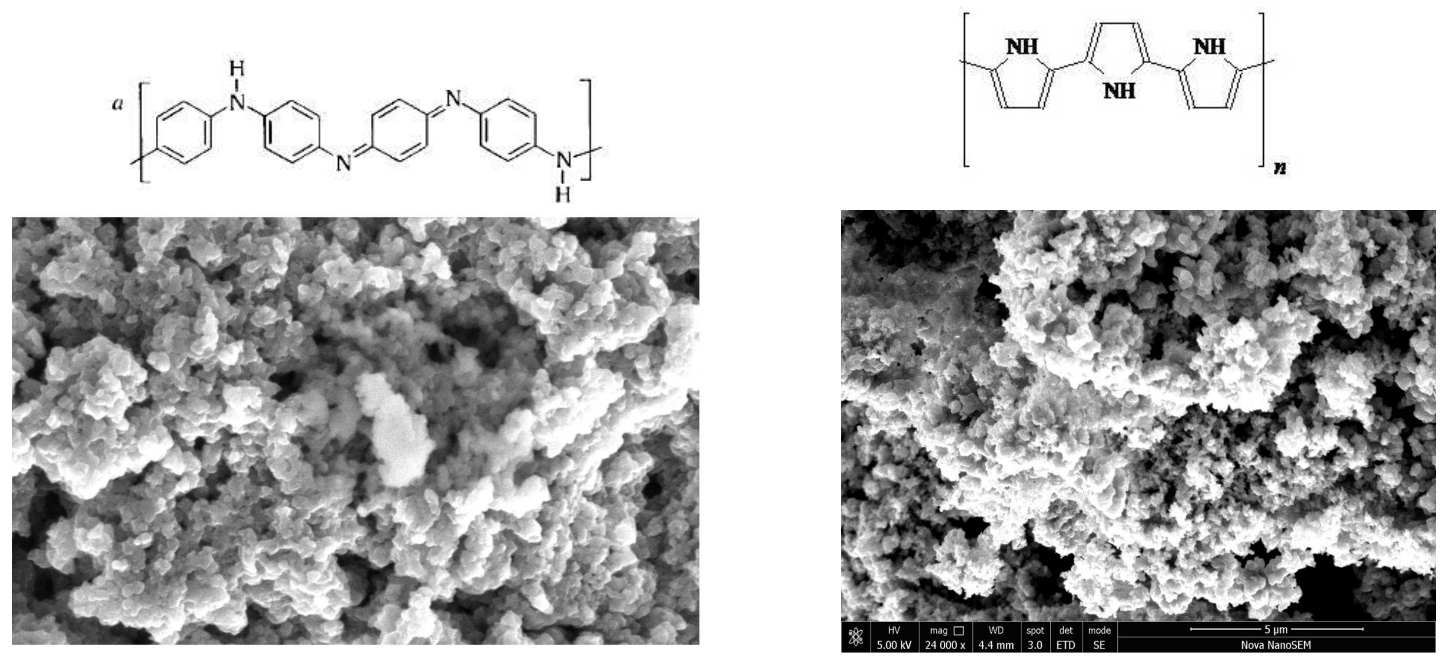

а 6

Рис. 1. Химическая формула полианилина (а), полипиррола (б) и структура полимеров по данным электронной сканирующей микроскопии. (Разрешение снимков одинаково)

Адсорбционный метод. Сорбцию биологических объектов на полимерные композиты проводили по методу, приведенному в работе [14]. После контакта биологических объектов с полимерами образованные в водных растворах комплексы (сорбент+биологический объект) осаждали из растворов при низкоскоростном центрифугировании при 3000 об./мин. Затем жидкую фазу - надосадок, а также осадок в виде сформированных комплексов: вирус+сорбент, бактерия+сорбент, исследовали на наличие биологической активности разными методами, в зависимости от вида объекта (вирус, бактерии).

\section{Обсуждение результатов}

Эксперимент проводили поэтапно. На первом этапе на все типы полимерных сорбентов осуществляли сорбцию вируса гриппа. Эффективность сорбции вируса определяли с помощью реакции гемагглютинации. Результаты по сорбции вирусов представлены в табл. 1.

Таблица 1. Исследование сорбции вируса гриппа В/Москва/04/2017 на PPy, PANI и их композиты с серебром

\begin{tabular}{|c|c|c|}
\hline \multirow{2}{*}{ Сорбент } & \multicolumn{2}{|c|}{ Титр вируса, ГАЕ } \\
& до сорбции & после сорбции \\
\hline PPy & \multirow{3}{*}{512} & 2 \\
\hline PPy-Ag & & 4 \\
PANI-Ag & \multirow{2}{*}{5} & 16 \\
\hline PANI- & & 8 \\
\hline
\end{tabular}

После добавления сорбентов в вируссодержащие растворы с начальным ГА титром 512 титр вируса в надосадке понижался от 16 до 2 ГАЕ, в зависимости от вида сорбента. Наибольшее падение в 256-128 раз зафиксировано для РРу и композита РРуAg. Наименьшее падение в 32 раза отмечено в случае композита PANI-Ag. Следует уточнить, что в эксперименте был использован аллантоисный вирус и в растворе

Иванова и др. / Сорбционные и хроматографические процессы. 2018. Т. 18. № 2 
кроме вирионов присутствовали в небольшом количестве аллантоисные белки куриного эмбриона. Полученные результаты находятся в полном соответствии с данными предыдущих исследований [1-4], которые показали интенсивное связывание вирусов полимерными сорбентами. Была показана также специфичность сорбции в зависимости от вида полимерного сорбента и штамма выделяемого вируса, которая приводила к изменению эффективности сорбции в несколько раз [2]. Ранее установлено, что после связывания с сорбентом вирус терял инфекционную активность, при этом, комплекс сорбент+вирус мог быть разрушен только под действием ультразвука с выделением нежизнеспособного вируса [15].

Следующий этап исследования заключался в проверке сорбции бактерий на исходные (без вируса) сорбенты. Выбор бактерий был обусловлен двумя критериями: значительной разницей в строении и возможностью водного пути передачи. Грамположительные (Грам(+)) бактерии - Staphylococcus aureus являются условнопатогенными микроорганизмами, которые присутствуют как у здоровых людей, с носительством у большинства в течение нескольких месяцев, они служит причиной многочисленных, опасных для жизни зооантропонозных инфекций. Стафилококки обнаруживаются в сточных водах, водоемах, водопроводной воде, продуктах питания, на кожных покровах людей и животных. Грамотрицательные (Грам(-)) бактеpии: Shigella flexneri 2a - возбудитель острой кишечной инфекции, характеризуется развитием вторичных иммунодефицитов, затяжных и хронических форм инфекционных заболеваний и имеет преимущественно водный путь распространения. Используемые Грам (+) и Грам (-) бактерии обладали существенным различием по форме и структуре мембраны [16]. Так Staphylococcus aureus Cowan Грам(+) имеет кокковидную форму. Ее однослойная мембрана содержит полимеры - пептидогликаны углевод-белковой природы, соединенные ковалентными связями с тейхоевыми кислотами, тейхуроновыми кислотами и липопротеинами. Грам(-) бактерии Shigella flexneri 2а имеют форму палочек и содержат две мембраны. Внешняя состоит из фосфолипидов белков липопротеина и липополисахарида, который имеет сложную структуру, локализован во внешнем слое, занимает 30-40 \% ее поверхности

Взвесь бактерий в физиологическом растворе, содержащем 5×105 КОЕ/мл, приводили в контакт с сорбентами. Анализ надосадка и выделенного низкоскоростным центрифугированием осадка показал (табл. 2), что бактерии активно сорбируются на полимерные сорбенты. После контакта с сорбентами остаточные бактерии в надосадке регистрировались только в случае PANI-Ag, при этом их количество было значительно меньше, чем до сорбции. Для Shigella flexneri $2 a$ наблюдали уменьшение количества в надосадке примерно 1000 раз, а для Staphylococcus aureus в 2.8 х $10^{3}$ раз. В случае других сорбентов в надосадке бактерии не регистрировались. Для всех типов сорбентов и видов бактерий в выделенных осадках бактерии не регистрировались (табл. 2), что говорит о том, что комплекс сорбент+бактерия не опасен в плане инфекционного заражения.

Основной эксперимент осуществлялся после подготовительных этапов и проводился с использованием комплексов «вирус+сорбент». Образцы содержащие комплексы вирус +сорбент, помещали водный раствор, в который добавляли бактерии, после чего следовала оценка эффективности сорбции каждого вида бактерий. Схема эксперимента представлена на рис. 2. Исследование осадка и надосадка при сорбции двух видов патогенов показало, что количество сорбированных бактерий сильно зависит от типа комплекса сорбент+вирус (табл. 2). В случае Shigella flexneri $2 a$ copбция на комплекс РРу+вирус практически отсутствовала: начальный и конечный титр бактерий в осадке и надосадке не различались и равнялись $10^{5} \mathrm{KOE/мл.} \mathrm{Противопо-}$ 
ложная картина имела место при сорбции на комплекс «РANI+вирус», где наблюдалась полная адсорбция Shigella flexneri $2 a$.

Таблица 2. Сорбция бактерий на исходные сорбенты и сорбенты, связанные с вирусом гриппа*

\begin{tabular}{|c|c|c|c|c|c|c|c|c|}
\hline & \multicolumn{6}{|c|}{ Концентрация бактерий в растворах после взаимодействия с сорбентами (КОЕ/мл) } \\
\cline { 2 - 9 } & \multicolumn{2}{|c|}{$\begin{array}{c}\text { PPy } \\
\text { Shigella flexneri 2a }\end{array}$} & \multicolumn{2}{|c|}{ РРу-Ag } & \multicolumn{2}{|c|}{ РАNI } & \multicolumn{2}{|c|}{ РANI-Ag } \\
\hline Патогены & осадок & надосадок & осадок & надосадок & осадок & надосадок & осадок & надосадок \\
\hline $\begin{array}{c}\text { Shigella } \\
\text { flexneri } \\
\text { 2a }\end{array}$ & 0 & 0 & 0 & 0 & 0 & 0 & 0 & $10^{2}$ \\
\hline $\begin{array}{c}\text { Shigella } \\
\text { flexneri } \\
\text { 2a + ви- } \\
\text { pyc }\end{array}$ & $10^{5}$ & $10^{5}$ & 0 & $8 \times 10^{2}$ & 0 & 0 & $4 \times 10^{1}$ & $10^{5}$ \\
\hline $\begin{array}{c}\text { Staph } \\
\text { aureus }\end{array}$ & 0 & 0 & 0 & 0 & 0 & 0 & 0 & $1.8 \times 10^{2}$ \\
\hline $\begin{array}{c}\text { Staph } \\
\text { aureus } \\
\text { +вирус }\end{array}$ & $10^{5}$ & $10^{3}$ & $4 \times 10^{2}$ & $5 \times 10^{2}$ & 9 & 11 & 0 & $10^{2}$ \\
\hline
\end{tabular}

*бактерия Shigella flexneri 2a, Staphylococcus.aureus Cowan, вирус В/Москва/04/2017.

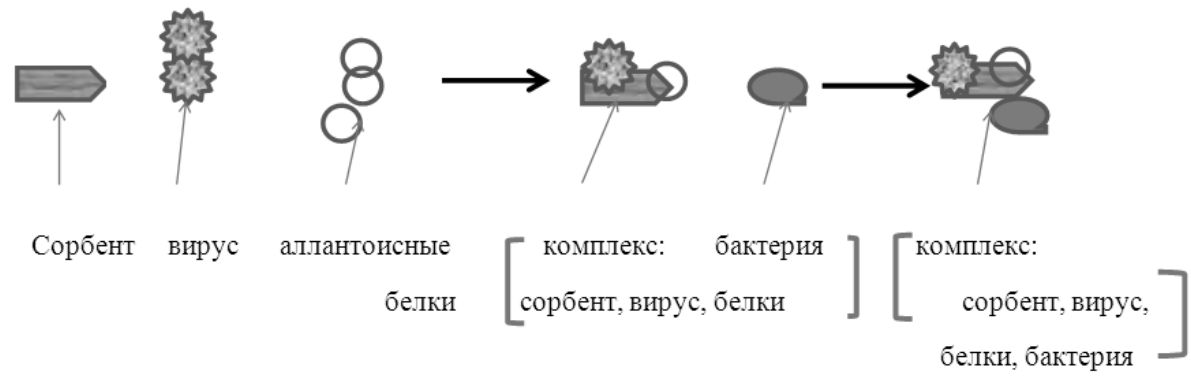

Рис. 2. Схема последовательной сорбции аллантоисных вирусов гриппа и бактерий на сорбент

При сорбции бактерии Staphylococcus aureus на комплекс «РРу+вирус» установлено падение титра бактерий в надосадке в 100 раз (с $10^{5}$ до $10^{3}$ КОЕ/мл) без снижения его в осадке. После контакта Staphylococcus aureus с комплексом PANI+вирус в осадке и надосадке обнаружены лишь единичные бактерии 9 и 11 $\mathrm{KOE} / \mathrm{cm}^{3}$.

Комплексы полимеров, содержащие Ag, а именно «РPy-Ag+вирус» и «PANI$\mathrm{Ag+вирус»,} \mathrm{по} \mathrm{эффективности} \mathrm{сорбции} \mathrm{бактерий} \mathrm{занимали} \mathrm{промежуточную} \mathrm{пози-}$ цию. Для Shigella flexneri $2 a$ более интенсивная сорбция наблюдалась на «РРу$\mathrm{Ag}+$ вирус» (осадок 0, надосадок $8 \times 10^{2} \mathrm{KOE}$ ). Для «PANI-Ag+вирус» сорбция Shigella flexneri $2 a$ была слабее (осадок $4 \times 10^{2}$, надосадок $10^{5} \mathrm{KOE} / \mathrm{cm}^{3}$ ). Обратная ситуация наблюдалась для Staphylococcus aureus, который активнее сорбировался на комплекce «PANI-Ag+вирус» (осадок 0, надосадок $10^{2} \mathrm{KOE} / \mathrm{cm}^{3}$ ) и менее активно на комплексе «РРу-Ag+вирус» (осадок $4 \times 10^{2}$, надосадок $\left.5 \times 10^{2} \mathrm{KOE} / \mathrm{cm}^{3}\right)$.

Таким образом, адсорбционная активность комплексов «сорбент+вирус» (В/Москва/04/2017) в отношении бактерий убывает в следующем ряду:

- для бактерий Shigella flexneri 2a: PANI>PPy-Ag>PANI-Ag $>$ PPy.

- для бактерий Staphylococcus aureus Cowan: PANI>PANI-Ag >PPy-Ag>PPy. 
Сравнение сорбции бактерий «свободными» сорбентами и комплексами сорбент+вирус свидетельствует, что при последовательной сорбции идет конкуренция за места связывания и образование связи патогенов с сорбентом, которая зависит как от структуры белков бактерий, так и от химической структуры полимеров.

Предварительные заключения по результатам экспериментов следующие:

- PРу активнее, чем PANI, связывает и удерживает вирус, поэтому, в случае предварительной сорбции вируса из концентрированного раствора, все сорбционные центры РРу оказываются блокированными вирусом и недоступны для бактерий.

- Для PANI сорбционная активность по отношению к вирусу несколько ниже, чем у РРу, поэтому эффективность связывание бактерий выше. Возможно, для PANI в какой-то степени реализуется конкурентная десорбция вирусов бактериями.

- Бактерии и, в первую очередь, Грам(-) бактерии, лучше связываются PANI, что можно объяснить наличием положительного заряда на полимерной цепи.

Присутствие в полимерной матрице сорбентов наночастиц серебра несколько повышает эффективность взаимодействия с бактериями, но не играет при этом решающую роль. Этот эффект, по-видимому, объясняется взаимодействием Ag c S-H группами, входящими в структуру биообразцов. Показано, что наибольшее сродство к ионам серебра обладают цистеин и гомоцистеин мембраны [17]. В конечном итоге эффективность сорбции определяется специфическим взаимодействием полимер патоген.

\section{Заключение}

Исследования поэтапной сорбции вируса, а затем Грам (+) и Грам (-) бактерий показывают, что полимерные материалы на основе PANI и PРу обладают способностью одновременно сорбировать представителей как оболочечных вирусов (вируса гриппа), так и различных видов бактерий, что позволяет использовать их для удаления всех типов микропатогенов, присутствующих в водных средах. Эффективность связывания сорбентами индивидуальных видов патогенов высока, однако конкурентная сорбция различных типов патогенов при высокой их концентрации требует дальнейшего изучения.

\section{Список литературы}

1. Сапурина И.Ю., Иванова М.В., Иванова В.Т., Бурцева Е.И. и др. // Высокомолекулярные соединения. Серия А. 2014.Т. 56. № 4. С. 389-398.

2. Иванова В.Т. Гарина Е.О., Николаева Т.Н., Суетина И.А. и др. // Вода: химия $и$ экология. 2016. № 10. С. 71-81.

3. Гарина Е.О., Иванова В.Т., Носик Н.Н., Кондрашина Н.Г. и др. // Нанотехнологии: разработка, применение - XXI век. 2016. Т. 8. № 2. C.3-13.

4. Иванов В.Ф., Гарина Е.О., Сапурина И.Ю., Грибкова О.Л. и др. // Физикохимия поверхности и защита металлов. 2016. Т. 52. № 2. C. 197-202.
5. Kamikawa T.L., Mikolajczyk M.G., Kennedy et al. // Biosens Bioelectron. 2010. Vol. 26. No 4. pp. 1346-1352.

6. Chandra S., Singh R., Singh H. Et al. Patent USA 6156202 A, 1999-03-30. https://www.google.com/patents/US6156202 (дата обращения 2 февраля 2018г. )

7. Mansour M.S. Ossman M.E., Farag H.E. // Desalination. 2011. Vol. 272 .pp. 301-305.

8. Bhaumik M. Maity A., Srinivasu V.V., Onyango M.S. // J. Hazard. Mater. 2011. No 190. pp. 381-390.

9. Shandry V., Kim K.S. // Chemical Communications. 2011. No 47. pp. 3242-3944.

10.Львов Д.К., Бурцева Е.И., Кириллова Е.С. и др. // Вопросы вирусологии. 2018. Т. 63. С. 61-65. 
11.Sapurina I., Lia Yu., Alekseeva E., Bober P. et al. // Polymer. 2017. Vol. 113. pp. 247258.

12.Huang W.-S., Humphrey B.D., MacDiarmid A.G. // J. Chem. Soc. Faraday Trans. 1. Phys. Chem. Condens. Phases., 1986, Vol. 82, No 8, pp. 2385-2400.

13.Stejskal J., Prokeš J., Sapurina I. // Materials Letters. 2009. No 63(8). pp. 709-711.

14.Иванова, В.Т. Иванов В.Ф., Грибова О.Л. и др. Патент РФ № 2372951 от 01.08.2007.

\section{References}

1. Sapurina I.Yu., Ivanova V.T., Ivanova M.V., Polymer Sci Series A, 2014, Vol. 56, pp. 450-458.

2. Ivanova V.T., Garina E.O., Nikolaeva T.N., Suetina I.A. et al., Water: Chemistry and Ecology, 2016, No 10, pp. 71-81.

3. Garina E.O., Ivanova V.T., Nosik N.N., Kondrashina N.G et al., Nanotechnology: development and application XX1 Century, 2016, Vol. 8, No 2, pp. 3-13.

4. Ivanov V.F., Garina E.O., Sapurina I.Yu., Gribkova O.L. etal., Protection of Metals and Physical Chemistry of Surfaces, 2016, Vol. 52, No 2, pp. 291-296.

5. Kamikawa T.L., Mikolajczyk M.G., Kennedy .et al., Biosens Bioelectron., 2010, Vol. 26, No 4, pp. 1346-1352.

6. Chandra S., Singh R., Singh H. et al., $P a-$ tent US 6156202 A, 1999-03-30. https://www.google.com/patents/US6156202

7. Mansour M.S. Ossman M.E., Farag H.E., Desalination, 2011, Vol. 272, pp. 301-305.

8. Bhaumik M., Maity A., Srinivasu V.V., Onyango M.S., J. Hazard. Mater., 2011, No 190, pp. 381-390.

Иванова Валерия Тимофеевна - д.б.н., ведущий научный сотрудник, лаб. этиологии и эпидемиологии гриппа ФГБУ «Национальный исследовательский центр эпидемиологии и микробиологии имени почетного академика $\mathrm{H}$. Ф. Гамалеи» Минздрава России, «НИЦЭМ им. Н.Ф. Гамалеи» Минздрава России, Москва

Морозова Екатерина Олеговна - научный сотрудник, лаб. лаб. этиологии и эпидемиологии гриппа ФГБУ «Национальный исследовательский центр эпидемиологии и микробиологии имени почетного академика $\mathrm{H}$. Ф. Гамалеи» Минздрава России, «НИЦЭМ им. Н.Ф. Гамалеи» Минздрава России, Москва
15.Иванова В.Т., Гарина Е.О., Сапурина И.Ю., Стейскал Я. И др. // Сорбциинные и хроматографические прочессы. 2017. Т.17. № 4. С. 592-600.

16.Нетрусов А.И., Котова И.В. Общая микробиология. М. ИЦ «Академия». 2007. С. 2527.

17.Новиков А.В., Бубляев Р.А., Краснов Н.В., Козьмин Ю.П. и др. // Научное приборостроение. 2007. Т. 17. № 4. С. 29-36.

9. Shandry V., Kim K.S., Chemical Communications. 2011, No 47, pp. 3242-3944.

10.Lvov D.K., Burtseva E.I., Kirillova E.S. et al., Problems of virology, 2018, Vol. 63, No 2, pp. 61-65.

11.Sapurina I., Lia Yu., Alekseeva E., Bober. P. et al., Polymer Volume, 2017, No 113, pp. 247-258.

12.Huang W.-S., Humphrey B.D., MacDiarmid A.G., J. Chem. Soc. Faraday Trans. 1 Phys. Chem. Condens. Phases., 1986, Vol. 82, No 8, pp. 2385-2400.

13.Stejskal J., Prokeš J., Sapurina I., Materials Letters, 2009, No 63(8), pp. 709-711.

14.Ivanova V.T., Ivanov V.F., Gribkova O.L., Patent № 2372951. RF. 01.08. 2007.

15.Ivanova V.T., Garina E.O., Sapurina I.Yu., Stejskal J. et al., Sortsionnye I khoromatograficheskie protsessy, 2017, Vol. 17, No 4, pp. 592600.

16. Netrusov A.I., Cotova I.V., General Microbiology, M., IC "Academy", 2007, pp. 25-27.

17.Novikov A.V., Bublyaev R.A., Krasnov N., Kozmin Yu. et al., Nauchnoe priborostroenie, 2007, Vol. 17, No 4, pp. 29-36.

Ivanova Valeria T. - Dr.Sci.(virology) Leading researcher, Lab of etiology and epidemiology of influenza, Federal State Budgetary Institution «National Research Center for Epidemiology \& Microbiology named after the honorary academician N.F. Gamaleya» of the Ministry of Health of Russian Federation, Moscow

Morozova Ekaterina O. - researcher, Lab of etiology and epidemiology of influenza «N.F. Gamaleya NRCEM», Moscow 
Николаева Татьяна Николаевна - д.м.н., (ведущий научный сотрудник, лаб естественного иммунитета, ФГБУ «Национальный исследовательский центр эпидемиологии и микробиологии имени почетного академика Н. Ф. Гамалеи» Минздрава России, «НИЦЭМ им. Н.Ф. Гамалеи» Минздрава России, Москва

Бурцева Елена Ивановна - д.м.н., (вирусология) рук. лаборатории этиологии и эпидемиологии гриппа ФГБУ «национальный исследовательский центр эпидемиологии и микробиологии имени почетного академика $\mathrm{H}$. Ф. Гамалеи» Минздрава России, «НИЦЭМ им. Н.Ф. Гамалеи» Минздрава России, Москва

Сапурина Ирина Юрьевна- д.Х.н., ведущий научный сотрудник, лаб. Анизотропных и структурированных полимерных систем, Институт Высокомолекулярных соединений РАН, Санкт-Петербург

Пронин Александр Васильевич - д.б.н., (иммунология) проф. Рук. лаборатории естественного иммунитета ФГБУ «Национальный исследовательский центр эпидемиологии и микробиологии имени почетного академика $\mathrm{H}$. Ф. Гамалеи» Минздрава России, «НИЦЭМ им. Н.Ф. Гамалеи» Минздрава России г. Москва «НИЦЭМ им. Н.Ф. Гамалеи» Минздрава России, Москва
Nicolaeva Tatiyna N. - Dr.Med .Sci( microbiology)Leading researcher, Lab Natural Immune System, «N.F. Gamaleya NRCEM», Moscow

Burtseva Elena I. - Dr.Med.Sci(virology), Head of the Lab. of etiology and epidemiology of influenza, «N.F. Gamaleya NRCEM», Moscow

Sapurina Irina Yu. - Dr.Sci. (Chem), Leading researcher, Lab Laboratory of anisotropic and structureted polymer sistems, Institute of Macromolecular Compounds, Russian Academy of Sciences, Saint-Petersburg, Russian Federation

Pronin A.V. Dr.Sci(Immunology)prof Head of the Lab Natural Immune System «N.F. Gamaleya NRCE», Moscow 